\title{
Analysis of Fiber deposition using Automatic Image Processing Method
}

\author{
M. Belka ${ }^{1}$, F. Lizal ${ }^{1}$, J. Jedelsky ${ }^{1}$, and M. Jicha ${ }^{1}$ \\ ${ }^{1}$ Brno University of Technology, Faculty of Mechanical Engineering, Energy Institute, Technicka 2896/2, Brno
}

\begin{abstract}
Fibers are permanent threat for a human health. They have an ability to penetrate deeper in the human lung, deposit there and cause health hazards, e.g. lung cancer. An experiment was carried out to gain more data about deposition of fibers. Monodisperse glass fibers were delivered into a realistic model of human airways with an inspiratory flow rate of $30 \mathrm{l} / \mathrm{min}$. Replica included human airways from oral cavity up to seventh generation of branching. Deposited fibers were rinsed from the model and placed on nitrocellulose filters after the delivery. A new novel method was established for deposition data acquisition. The method is based on a principle of image analysis. The images were captured by high definition camera attached to a phase contrast microscope. Results of new method were compared with standard PCM method, which follows methodology NIOSH 7400, and a good match was found. The new method was found applicable for evaluation of fibers and deposition fraction and deposition efficiency were calculated afterwards.
\end{abstract}

\section{Introduction}

Fibers are particles that have one dimension significantly greater than the other two. They are usually characterized by aspect ratio, the ratio of their length to their diameter. Because of their specific shape, fibers can easily penetrate deep into the human airways and deposit there. Length of the fibers is also important during removal of particles from the lung. Their length can be greater than the diameter of macrophages, which normally remove particle from the lungs. Macrophages die in the process of removing a fiber and release inflammatory cytokines, which can cause health issues. In the past, research was aimed mainly at asbestos fibers and in 1989 they were classified as a Group A, human carcinogen [1]. The use of asbestos was banned afterwards. Asbestos were then substituted by man-made vitreous fibers (MMVFs), which are nowadays matter of great concern as a potential health hazard.

\section{Methods}

\subsection{Acquisition of samples}

Experiment setup for fiber deposition studies in a model of human lungs is presented in figure 1 and more details about settings were published by Wang et al [2] and Lizal et al [3]. The setup consists of a fiber generator, a neutralizer, a classifier, a dilutor, a realistic model of human lungs, 10 output filters, 10 flow meters and a vacuum pump. Polydisperse fibers were dispersed by the generator from a mixture of JM-100 glass fibers and sodalime glass beads. Static charge was removed from these fibers and they were classified in the classifier. Average diameter of monodisperse fibers passing through the classifier was $1 \mu \mathrm{m}$, average length was $10 \mu \mathrm{m}$ and density $2.56 \mathrm{~g} / \mathrm{cm}^{3}$.

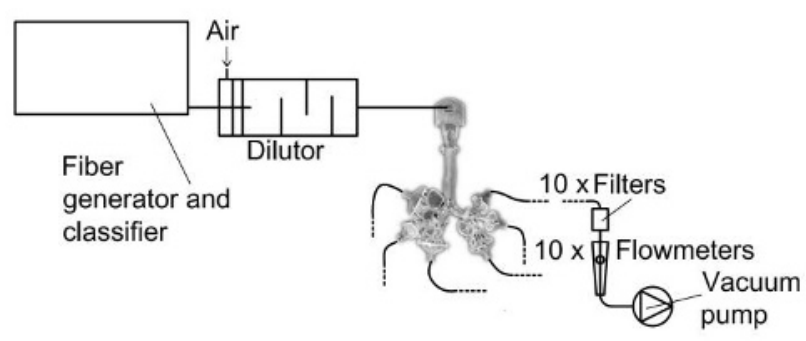

Fig. 1. Experiment setup

Monodisperse fibers were mixed with air in the dilutor and then flew to the realistic segmented model of human lungs, which contained airways from an oral cavity up to the seventh generation of branching. The inner surface of the model was coated by silicon oil to prevent bouncing of fibers from the wall. Fibers, that did not deposit in the model were collected on nitrocellulose membrane output filters.

The experiment lasted 4 hours and output filters were changed every half an hour to prevent overfilling. The model was disassembled into segments after the exposure to fibers. Each segment was put into a beaker with isopropanol and sonicated to release fibers into a solvent. After that the solvent was filtrated through nitrocellulose 
membrane filters and the filters were dried out in dustless environment. Dry filters were mounted on microscope slides and made transparent by acetone vapours. Output filters were mounted on microscope slides as well and made transparent. There were 32 filters from the segments of the model and 80 filters from the output.

\subsection{Analysis of samples}

Ordinarily, analysis of filters with fibers follows methodology NIOSH 7400 [4]. This method uses phase contrast microscopy (PCM) and gives rules for manual counting of fibers, such as minimum aspect ratio of fibers, minimum length etc. However, this method is time consuming and requires high concentration of a microscopist. It also depends on subjective attributes of the microscopist, such as a good health, mood etc. This is why there was established new automatic method for analysis of filters. High resolution camera Atik 314 E was mounted on a microscope Nikon Eclipse 200 and phase contrast objective was used. High quality images of every filter were taken and new software was created for detection and counting of fibers. The software processes every picture in several steps (figure 2).
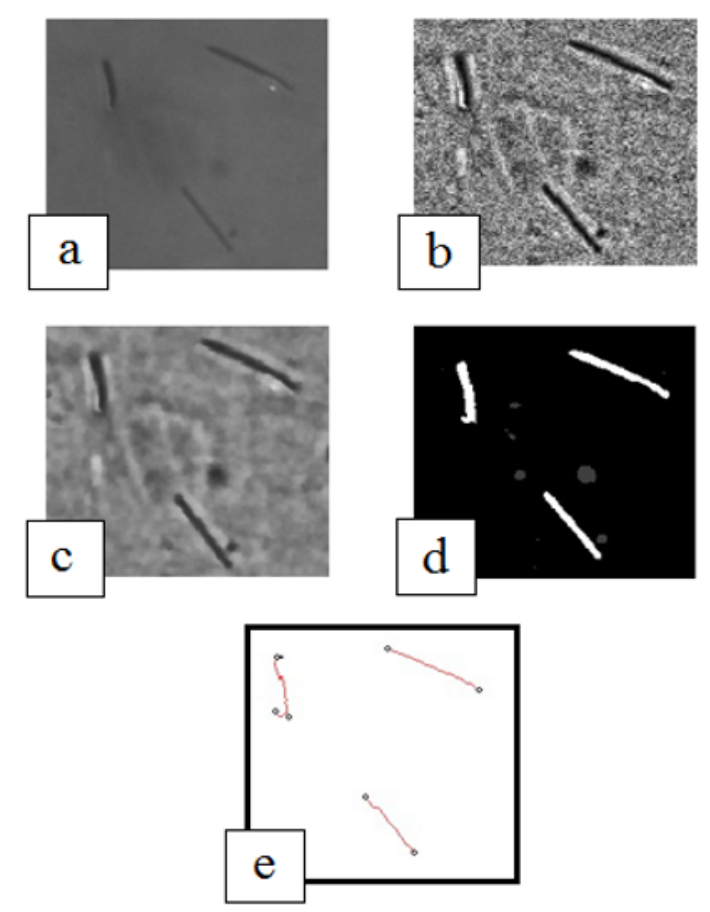

Fig. 2. Steps of the image processing : a) original picture, b) adaptive contrast control method, c) rotating Gaussian kernel, d) segmentation, e) detected fiber endings

The original picture is down-scaled and median filter is used for homogenization of the background of the picture and removing small objects. After that adaptive contrast control (ACC) method is applied to enhance fine details. Unfortunately ACC method enhances also additive noise. Therefore, linear filter with rotating Gaussian kernel is used to reduce the noise. The next step is image segmentation using threshold method, which identifies fibers and also other objects. Objects that are not fiber are removed according to their shape or size.
The final step is counting of fibers, which is based on analysis of fiber endings, because fibers can overlap or create agglomerates. Amount of fiber endings is divided by 2 and final amount of fibers is displayed.

10 filters were chosen randomly to ascertain the precision of results given by the software. Both manual and automatic analyses of the filters were accomplished and results were compared. After that all the filters from the experiment were analysed and deposition characteristics were calculated.

\section{Results and discussion}

Manual counting followed methodology NIOSH 7400 and was completed by 3 laboratory technicians. Arithmetic means of their results were calculated and are displayed in table 1 .

Table 1. Manual method

\begin{tabular}{|c|c|c|c|c|}
\hline $\begin{array}{c}\text { filter } \\
\text { number }\end{array}$ & $\begin{array}{c}\text { technician } \\
1\end{array}$ & $\begin{array}{c}\text { technician } \\
2\end{array}$ & $\begin{array}{c}\text { technician } \\
3\end{array}$ & $\begin{array}{c}\text { arithmetic } \\
\text { means }\end{array}$ \\
\hline 1 & 144665 & 137481 & 176859 & 153002 \\
\hline 2 & 198414 & 182248 & 158621 & 179761 \\
\hline 3 & 45735 & 42971 & 34957 & 41221 \\
\hline 4 & 344461 & 310333 & 220107 & 291634 \\
\hline 5 & 203250 & 190815 & 155996 & 183353 \\
\hline 6 & 108188 & 96996 & 85943 & 97042 \\
\hline 7 & 241662 & 227568 & 223561 & 230931 \\
\hline 8 & 101694 & 86910 & 71711 & 86772 \\
\hline 9 & 236549 & 185841 & 226463 & 216284 \\
\hline 10 & 84975 & 70053 & 61348 & 72125 \\
\hline
\end{tabular}

Relative errors were calculated using equation 1.

$$
\mu=\frac{y-y^{*}}{y^{*}}
$$

where $y$ is amount of fibers counted by technician and $y^{*}$ is probable correct value, which is arithmetic mean of results of all laboratory technicians. Relative errors are presented in table 2 .

Table 2. Relative errors of manual method

\begin{tabular}{|c|c|c|c|}
\hline filter number & technician 1 & technician 2 & technician 3 \\
\hline 1 & $5 \%$ & $10 \%$ & $16 \%$ \\
\hline 2 & $10 \%$ & $1 \%$ & $12 \%$ \\
\hline 3 & $11 \%$ & $4 \%$ & $15 \%$ \\
\hline 4 & $18 \%$ & $6 \%$ & $25 \%$ \\
\hline 5 & $11 \%$ & $4 \%$ & $15 \%$ \\
\hline 6 & $11 \%$ & $0 \%$ & $11 \%$ \\
\hline 7 & $5 \%$ & $1 \%$ & $3 \%$ \\
\hline 8 & $17 \%$ & $0 \%$ & $17 \%$ \\
\hline 9 & $9 \%$ & $14 \%$ & $5 \%$ \\
\hline 10 & $18 \%$ & $3 \%$ & $15 \%$ \\
\hline
\end{tabular}


The average value is $10 \%$, which agrees with methodology NIOSH 7400. After that the same filters were analyzed by automatic method. The results are presented in table 3 .

Table 3. Automatic method

\begin{tabular}{|c|c|c|c|c|c|}
\hline $\begin{array}{c}\text { filter } \\
\text { number }\end{array}$ & 1 & 2 & 3 & 4 & 5 \\
\hline $\begin{array}{c}\text { amount } \\
\text { of fibers }\end{array}$ & 211702 & 250213 & 109804 & 383732 & 256668 \\
\hline $\begin{array}{c}\text { filter } \\
\text { number }\end{array}$ & 6 & 7 & 8 & 9 & 10 \\
\hline $\begin{array}{c}\text { amount } \\
\text { of fibers }\end{array}$ & 142730 & 278570 & 148750 & 313165 & 112487 \\
\hline
\end{tabular}

Relative errors were calculated using equation 1 , where $y_{*}$ is amount of fibers detected by automatic method and $y^{*}$ is arithmetic mean of results of manual method. Results are presented in table 4.

Table 4. Relative errors of automatic method

\begin{tabular}{|c|c|c|c|c|c|}
\hline filter number & 1 & 2 & 3 & 4 & 5 \\
\hline relative error & $38 \%$ & $39 \%$ & $166 \%$ & $32 \%$ & $40 \%$ \\
\hline filter number & 6 & 7 & 8 & 9 & 10 \\
\hline relative error & $47 \%$ & $21 \%$ & $71 \%$ & $45 \%$ & $56 \%$ \\
\hline
\end{tabular}

Results of the automatic method differed from the manual method and average relative error was around $55 \%$. The reason of that was in sensitivity of the method. Software identified non-fibrous objects as fibers or split fiber into more fibers. Therefore, every analysed image was checked by laboratory technician and wrong detections were fixed in the software, which offers post-processing. Results of edited automatic analysis are presented in table 5 .

Table 5. Edited automatic method

\begin{tabular}{|c|c|c|c|c|c|}
\hline $\begin{array}{c}\text { filter } \\
\text { number }\end{array}$ & 1 & 2 & 3 & 4 & 5 \\
\hline $\begin{array}{c}\text { amount of } \\
\text { fibers }\end{array}$ & 122680 & 186147 & 46924 & 356715 & 185432 \\
\hline $\begin{array}{c}\text { filter } \\
\text { number }\end{array}$ & 6 & 7 & 8 & 9 & 10 \\
\hline $\begin{array}{c}\text { amount of } \\
\text { fibers }\end{array}$ & 86197 & 217732 & 78806 & 216689 & 54804 \\
\hline $\begin{array}{c}\text { filter } \\
\text { number }\end{array}$ & 1 & 2 & 3 & 4 & 5 \\
\hline $\begin{array}{c}\text { relative } \\
\text { error }\end{array}$ & $3 \%$ & $33 \%$ & $46 \%$ & $57 \%$ & $30 \%$ \\
\hline $\begin{array}{c}\text { filter } \\
\text { number }\end{array}$ & 6 & 7 & 8 & 9 & 10 \\
\hline $\begin{array}{c}\text { relative } \\
\text { error }\end{array}$ & $14 \%$ & $21 \%$ & $17 \%$ & $29 \%$ & $2 \%$ \\
\hline
\end{tabular}

Average value of relative errors decreased to $25 \%$, but there was still difference between automatic and manual method even if every picture was checked after detection.
Because of this, correction coefficient was introduced. Correction coefficient was calculated using equation 2 .

$$
k=\frac{B}{C}
$$

where $B$ is average amount of fibers counted by manual method and $C$ is average amount of fibers counted by edited automatic method. The value of correction coefficient is 0.78 . Amounts of fibers counted by edited automatic method were multiplied by correction coefficient and the results are presented in table 6 .

Table 6. Corrected automatic method

\begin{tabular}{|c|c|c|c|c|c|}
\hline $\begin{array}{c}\text { filter } \\
\text { number }\end{array}$ & 1 & 2 & 3 & 4 & 5 \\
\hline $\begin{array}{c}\text { amount of } \\
\text { fibers }\end{array}$ & 122680 & 186147 & 46924 & 356715 & 185432 \\
\hline $\begin{array}{c}\text { filter } \\
\text { number }\end{array}$ & 6 & 7 & 8 & 9 & 10 \\
\hline $\begin{array}{c}\text { amount of } \\
\text { fibers }\end{array}$ & 86197 & 217732 & 78806 & 216689 & 54804 \\
\hline $\begin{array}{c}\text { filter } \\
\text { number }\end{array}$ & 1 & 2 & 3 & 4 & 5 \\
\hline $\begin{array}{c}\text { relative } \\
\text { error }\end{array}$ & $20 \%$ & $4 \%$ & $14 \%$ & $22 \%$ & $1 \%$ \\
\hline $\begin{array}{c}\text { filter } \\
\text { number }\end{array}$ & 6 & 7 & 8 & 9 & 10 \\
\hline $\begin{array}{c}\text { relative } \\
\text { error }\end{array}$ & $11 \%$ & $6 \%$ & $9 \%$ & $0 \%$ & $24 \%$ \\
\hline
\end{tabular}

Average relative error of the latest results is around $11 \%$, which is comparable with relative error between technicians using manual method. Automatic analysis consists of these steps: detection and counting of fibers by software, post-processing and multiplying the results by corrective coefficient.

Filters from the experiment were analysed by the automatic method. Unfortunately, filters created by rinsing the segments of the model contained too many non-fibrous objects and other particles. Thus, it was impossible to analyse them by the automatic method and they had to be analysed manually.

After that, deposition characteristics were calculated. Deposition fraction is the ratio of amount of deposited fibers in the given segment to amount of fibers entering the model. Deposition efficiency is the ratio of amount of deposited fibers in the given segment to amount of fibers entering the segment. Deposition characteristics are presented in figure 3. Both deposition fraction and deposition efficiency in a model are very low. It means that most of the fibers flew through the model and deposited on output filters. More details about calculated deposition characteristics were published by Lízal [2]. The automatic method proved to be applicable for analysing filters with fibers. It saves time and does not need high attention of microscopist. However, high quality pictures are necessary for this method. 


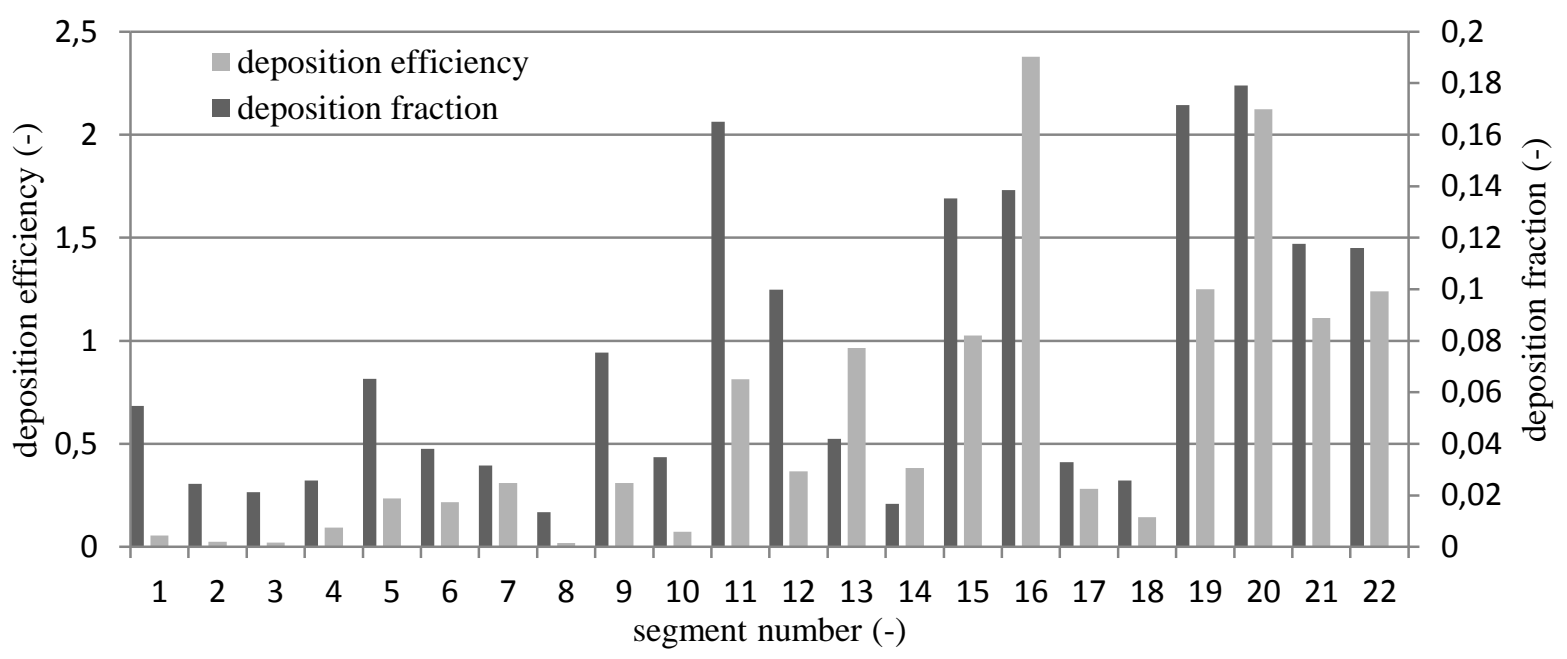

Fig. 3. Deposition characteristics

\section{Summary}

New automatic method was applied to study deposition of fibers. Segmented model of human airways from oral cavity up to the seventh generation of branching was exposed to fibers. Fibers that flew through the model were deposited on output filters. After that the fibers were rinsed from the model and deposited on nitrocellulose filters. Both, filters from the model and output filters, were made transparent using acetone vapours. Novel software was created to analyse filters with fibers. To ascertain its precise results, 10 randomly chosen filters were analysed both manually and by the software. Manual counting of fibers followed methodology NIOSH 7400. Results of manual and automatic method were compared and a good match was found. Average relative error was around $11 \%$. After that, automatic software was used to analyze filters from the experiment. Unfortunately, high quality image are necessary for analysis by the software therefore only output filters could be analyzed by the automatic method and filters from the model had to be analyzed manually. Deposition characteristics were calculated afterwards. Both deposition fraction and deposition efficiency were low, which is caused by a tendency of fibers to align with the flow. Aim of next experiments will be to ensure high quality of filters from the model and to upgrade the software so it can measure length and other attributes of fibers.

\section{Acknowledgement}

This work was supported by the Czech Grant Agency under the grant GA P105/11/1339, by COST Action 0806 project OC10052, by project ME 09030 of the program KONTAKT supported by the Czech Ministry of Education, Youth and Sports and by the project FSI-S11-6. The authors gratefully acknowledged support from Hana Druckmüllerová and Pavel Štarha for compiling the sotfware and Šárka Valášková for help.

\section{References}

1. P. A. Baron, Industrial Health (2001).

2. Z. Wang, P. K. Hopke, P. A. Baron, G. Ahmadi, Y.-S. Cheng, G. Deye, and W.-C. Su, Aerosol Science and Technology 39 (11), 1056 (2005).

3. F. Lízal, J. Elcner, M. Bělka, J. Jedelský, P. Hopke, M. Jícha, P. Štarha, and H. Druckmüllerová, 31.Setkání kateder mechaniky tekutin a termomechaniky, 2012.

4. Centers for disease control and prevention, http://www.cdc.gov/niosh/docs/2003154/method-8000.html 